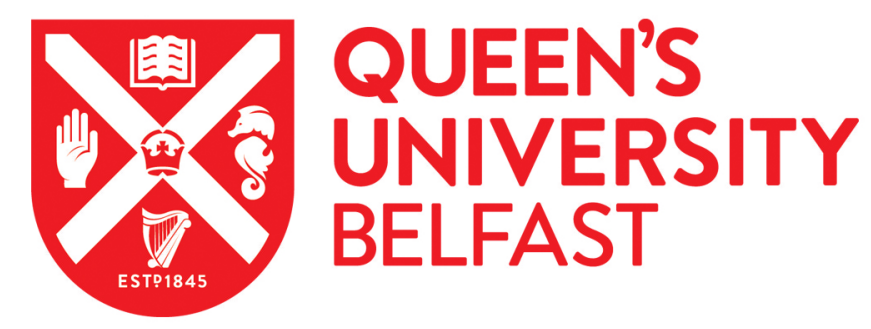

\title{
Fixed Dose Combination Formulations: Multi-Layered Platforms Designed for the Management of Cardiovascular Disease
}

\author{
Andrews, G. P., Li, S., Almajaan, A., Yu, T., Martini, L., Healy, A. M., \& Jones, D. S. (2019). Fixed Dose \\ Combination Formulations: Multi-Layered Platforms Designed for the Management of Cardiovascular Disease. \\ Molecular Pharmaceutics, 16(5), 1827-1838. https://doi.org/10.1021/acs.molpharmaceut.8b01068
}

Published in:

Molecular Pharmaceutics

Document Version:

Peer reviewed version

Queen's University Belfast - Research Portal:

Link to publication record in Queen's University Belfast Research Portal

Publisher rights

(c) 2019 American Chemical Society. This work is made available online in accordance with the publisher's policies. Please refer to any applicable terms of use of the publisher.

\section{General rights}

Copyright for the publications made accessible via the Queen's University Belfast Research Portal is retained by the author(s) and / or other copyright owners and it is a condition of accessing these publications that users recognise and abide by the legal requirements associated with these rights.

Take down policy

The Research Portal is Queen's institutional repository that provides access to Queen's research output. Every effort has been made to ensure that content in the Research Portal does not infringe any person's rights, or applicable UK laws. If you discover content in the Research Portal that you believe breaches copyright or violates any law, please contact openaccess@qub.ac.uk. 


\section{Article}

\section{Fixed Dose Combination Formulations: Multi-Layered Platforms Designed for the Management of Cardiovascular Disease}

Gavin P. Andrews, Shu Li, Ammar Almajaan, Tao Yu, Luigi Martini, Anne Marie Healy, and David S. Jones

Mol. Pharmaceutics, Just Accepted Manuscript • DOI: 10.1021/acs.molpharmaceut.8b01068 • Publication Date (Web): 31 Jan 2019

Downloaded from http://pubs.acs.org on February 18, 2019

\section{Just Accepted}

"Just Accepted" manuscripts have been peer-reviewed and accepted for publication. They are posted online prior to technical editing, formatting for publication and author proofing. The American Chemical Society provides "Just Accepted" as a service to the research community to expedite the dissemination of scientific material as soon as possible after acceptance. "Just Accepted" manuscripts appear in full in PDF format accompanied by an HTML abstract. "Just Accepted" manuscripts have been fully peer reviewed, but should not be considered the official version of record. They are citable by the Digital Object Identifier (DOI®). "Just Accepted" is an optional service offered to authors. Therefore, the "Just Accepted" Web site may not include all articles that will be published in the journal. After a manuscript is technically edited and formatted, it will be removed from the "Just Accepted" Web site and published as an ASAP article. Note that technical editing may introduce minor changes to the manuscript text and/or graphics which could affect content, and all legal disclaimers and ethical guidelines that apply to the journal pertain. ACS cannot be held responsible for errors or consequences arising from the use of information contained in these "Just Accepted" manuscripts. 
Fixed Dose Combination Formulations: Multi-Layered Platforms Designed for the Management of Cardiovascular Disease

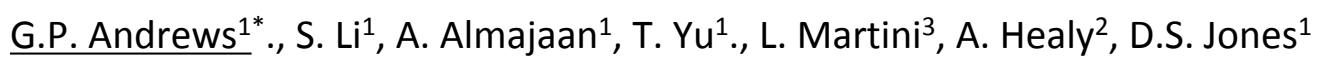

$5{ }^{1}$ Pharmaceutical Engineering Group, School of Pharmacy, Queen's University, Belfast BT9, UK.

${ }^{2}$ School of Pharmacy and Pharmaceutical Sciences, Panoz Institute, Trinity College Dublin, Dublin 2 , Ireland.

${ }^{3}$ Royal Pharmaceutical Society, East Smithfield, London, E1W 1AW

${ }^{*}$ Correspondence to: Gavin P. Andrews

15 (Telephone: +44-2890-97-2646; E-mail:g.andrews@qub.ac.uk) 


\begin{abstract}
Hyperlipidaemia is considered as one of the main risk factors associated with cardiovascular diseases (CVDs). Among different lipid-lowering agents used to manage hyperlipidaemia, statins are highly prescribed for management of hyperlipidaemia with simvastatin being one of the most common. Simvastatin is susceptible to extensive metabolism by CYP450 3A4 and $3 A 5$ which are expressed both in the liver and the gastrointestinal tract. Nevertheless, the localization of these enzymes is site dependent with lower concentration at the distal/proximal regions of the small intestine/colon. In addition to statins, medications such as antihypertensive and anti-coagulants are introduced as adjuvants, for the treatment of cardiovascular disease. The aim of this study was to design a bi-layer delivery system capable of delivering bi-phasic release of Simvastatin and Aspirin, within a fixed dose combination. A delayed release platform based on a combination of anionic polymers prepared using hot melt extrusion was developed to delay the release of simvastatin. An optimized formulation was tested for dissolution performance clearly demonstrated an ability to delay the release of Simvastatin. In addition, an immediate release layer based on Kollidon VA64 was successfully developed to deliver Aspirin. Both formulations were then manufactured as a bilayer drug delivery system (tablets and co-extrudates) and the release performance examined. Based on the obtained results, these formulations may be used as a platform for delivering a wide range of medications in a bi-phasic manner.
\end{abstract}

Keywords: Fixed-dose combination, hot-melt coextrusion, multilayer drug delivery, bi-phasic drug release, simvastatin, enhanced bioavailability. 


\section{Introduction}

According to the world health organization (WHO), cardiovascular diseases (CVDs) are the 45 leading cause of morbidity and mortality worldwide ${ }^{1,2}$. The main risk factors associated with CVDs are smoking, hypertension and dyslipidaemia. Amongst them, dyslipidaemia is considered the predominant risk ${ }^{3}$. The National Institute for Health and Care Excellence (NICE) guidelines for medicine-based CVD management following an acute myocardial infarction and/or stroke (secondary prevention) includes the use of agents such as aspirin,

50 angiotensin converting enzyme inhibitors (ACE inhibitors), $\beta$-blockers, thiazide-like diuretics and statins. However, for patients without a prior history of cardiovascular events (primary prevention), recent trial evidence has been cited in support of the recommendation of calcium channel blockers (CCBs), as an alternative to $\beta$-antagonists. It is therefore clear that, whilst blood pressure (BP) regulators may be varied between primary and secondary prevention, low dose aspirin and a statin are consistently administered 4,5 .

The mechanism by which statins lower the high level of LDL is through the effective inhibition of 3-hydroxy,3-methylglutaryl coenzyme A reductase (HMG-co-A) which mediates the synthesis of cholesterol ${ }^{6}$. Endogenous production of cholesterol is at its highest at night, hence, the administration time of a statin exhibiting a short half-life (e.g., simvastatin, 60 lovastatin and fluvastatin), becomes critical, if drug concentration in the body is to match cholesterol biosynthesis in the liver ${ }^{7}$. According to prescription cost analysis (PCA) for England in 2017 , simvastatin represented more than $37 \%$ of all statins prescribed, at a total cost of f28.7 million ${ }^{8}$. Despite this, it is interesting to note that the bioavailability of simvastatin is extremely poor (less than 5\%) due to the fact that it is considered a BCS class II drug and a

65 CYP 3 A substrate ${ }^{9}$. Being a Class II compound, it has poor solubility in GI fluids. Therefore, enhancing the solubility of simvastatin using enabling technologies represents an exciting means of improving the pharmacokinetics and hence bioavailability of this drug.

In addition, Simvastatin (SIM) is marketed as a prodrug in the lactone form with conversion to the active metabolite, open-chain $\beta$-hydroxyl acid, in the Gl tract. Importantly,

70 simvastatin either in the acid or lactone form are rapidly and irreversibly cleared by enzymatic oxidation. Enterocytes, which are located mainly in the villi tips of jejuna mucosa, contain virtually all types of drug-metabolising enzymes found in the liver (CYP 3A). Moreover, the localisation of CYP $3 \mathrm{~A}$ in the gut is regional with higher levels in the jejunum, slightly 
decreased levels in the duodenum, and significantly decreased levels in the ileum, caecum and colon. Protecting the drug from the hostile environment of the upper GIT may enhance therapeutic activity ${ }^{10}$. Moreover, lower statin dosing may be achievable with improved bioavailability, thus reduce the risk of adverse events.

While co-administer low-dose aspirin (ASP) with statins is hightly recommentded as stated previously, long-term and multiple dosage regimes, typical of CVD, often lead to poor patient compliance, reduced clinical efficacy, and, an increased risk of CVD related complications. Fixed-dose combination products (FDCs) negate the need for complex treatment regimens and are deemed preferable in long-term disease management. In this particular case where ASP and delayed release SIM are combined, ASP shows good solubility in Intestinal fluids due to its low pKa (3.5). However, given the acidic nature of aspirin, release 85 of the drug at the same site as simvastatin may alter microenvironment $\mathrm{pH}$ limiting simvastatin lactone to $\beta$-hydroxyl acid hydrolysis and solubility of $\beta$-hydroxyl acid. Separating APS and SIM into different layers is, therefore, considered necessary for achieving optimal therapeutic outcome.

In respect to manufacturing multi-layered FDCs, processes must be used that produce 90 robust drug delivery platforms that consistently deliver the required amount of drug to the patient, at the optimum rate, in order to achieve the desired therapeutic effect. Importantly, the processes used must also be capable of operating at full production scale with an associated high throughput. Undoubtedly, current processes used to manufacture multi-layer FDCs are sub-optimal and suffer from a number of significant disadvantages. Alternatively, 95 hot melt extrusion (HME), an innovative continuous manufacturing platform, may provide a more efficient means of manufacturing complex oral dosage forms ${ }^{11-14}$. Hot melt coextrusion (HMCE), has been used to manufacture multilayer drug delivery systems ${ }^{15,16}$. In reference to this emerging view of advanced pharmaceutical manufacturing, this article addresses the design, manufacture and characterization of clinically relevant FDCs using 100 extrusion technology. Solid dosage forms containing ASP and SIM to provide FDCs that offer an immediate release of low-dose ASP, and a delayed release of SIM to where it is optimally effective, have been engineered. Moreover, by targeting the release of SIM to the distal regions of the GI tract, enzymatic metabolism in the gut may be limited, resulting in improved bioavailability (higher plasma levels). In this study, HME was used for the manufacturing of 105 an immediate release ASP formulation and an enabling site-specific SIM formulation. As a 
proof of concept, the aforementioned formulations were also subjected to HMCE with minimal formulation variation to prepare bi-layered, bi-phasic drug delivery systems in a single-step manner. 


\section{Materials and Methods}

\section{Materials}

Acetylsalicylic acid (ASP) and polyethylene glycol 200 were purchased from sigma Aldrich (U.K.) and Simvastatin (SIM) was purchased from Kemportek (U.K). Hydroxypropyl methyl cellulose acetate succinate (HPMCAS) HF and MF grades were gifts from Shin-Etsu (Japan),

115 methyl methacrylate co-acrylic acid (Eudragit ${ }^{\circledR}$ L100), ethyl acrylate co-acrylic acid (Eudragit ${ }^{\circledR}$ L100-55), aminomethyl methacrylate (Eudragit ${ }^{\circledR}$ EPO) were kindly supplied by Evonik (Germany) and polyvinyl pyrrolidone-vinyl acetate (Kollidon ${ }^{\circ}$ VA64) and polyvinyl caprolactam-polyvinyl acetate-polyethylene glycol graft copolymer (Soluplus ${ }^{\oplus}$ ) were supplied by BASF (Germany). Triethyl citrate (TEC) was purchased from Lancaster synthesis 120 (U.K.). All other materials were of analytical grade and were used as supplied.

\section{Methods}

\section{Thermogravimetric Analysis (TGA)}

Thermal decomposition behaviour of individual materials was evaluated using

125 thermogravimetric analysis. A Thermal Advantage model Q500 (TA instrument, Leatherhead, U.K.) was used in all analyses. Samples of 5-10 mg were loaded into aluminium pans (TA Instrument, USA) and were ramped across a temperature range from $25-300^{\circ} \mathrm{C}$ at heating rate of $10^{\circ} \mathrm{C} / \mathrm{min}$. Nitrogen was used as purge gas at flow rate of $60 \mathrm{ml} / \mathrm{min}$ to maintain an inert atmosphere. Percent mass loss was recorded as a function of temperature during measurements and samples were analysed in triplicate.

\section{Differential Scanning Calorimetry (DSC)}

Thermal behaviour of all formulation components and extrudate was evaluated using a DSC 8000 power compensation dual furnace differential scanning calorimeter (Perkin-Elmer, 135 Windsor, Berkshire, UK). The instrument was calibrated with indium and zinc for heat of fusion and melting point, respectively. 3-5 $\mathrm{mg}$ of sample was accurately weighted into DSC pans (PerkinElemer, Berkshier, U.K.) and crimped using aluminium lids. Samples were analysed in a heat/cool/heat procedure using a heating rate of $200^{\circ} \mathrm{C} / \mathrm{min}$ across the range between $-60^{\circ} \mathrm{C}$ and $200^{\circ} \mathrm{C}$. In all cases dry helium was used as purging gas at flow rate of 40 
$140 \mathrm{ml} / \mathrm{min}$. Samples were analysed in triplicate and heat flow was recorded as a function of temperature.

\section{Powder X-ray diffraction}

Prior to PXRD analysis, pelletized extrudates were milled in a ball-milling chamber for two 145 intermittent (rest period of 20 seconds) 30 s periods with a frequency of $1 / 25 s^{-1}$. Powdered samples were immediately analysed at room temperature using a MiniFlex II Desktop Powder X-ray Diffractometer (Rigaku Corporation, Kent, England) equipped with Cu K $\beta$ radiation, at a voltage of $30 \mathrm{kV}$ and a current of $15 \mathrm{~mA}$. The powders were gently consolidated on a glass top-loading sample holder with $0.2 \mathrm{~mm}$ depression. All samples were scanned within the angular range of $3-45^{\circ} 2 \vartheta$ in continuous mode with a sample width of $0.03^{\circ}$ and a scan speed of $2.0^{\circ}$ min. Formulations components were individually analysed prior to extrusion using similar conditions.

\section{Preparation of solid dispersions using HME}

155 Preliminary assessment of polymers processability for both ASP and SIM was investigated using a co-rotating conical twin-screw extruder (HAAKE minilab, Thermo Electron Corporation, Stone, Staffordshire, UK). All formulations were processed at $50 \mathrm{rpm}$ and with different temperatures ranging from $100^{\circ} \mathrm{C}$ to $140^{\circ} \mathrm{C}$ tried for processability. The physical mixtures of desirable formulations (processable at relatively low temperature and showed desired dissolution behaviour) of both ASP and SIM formulations were then extruded using a Rondol $^{\circledast}$ fully-intermeshing co-rotating $10 \mathrm{~mm}$ twin-screw extruder (Rondol Industries SAS, Strasbourg, France) equipped with a $2 \mathrm{~mm}$ diameter cylindrical die. The screw configuration adopted contained a range of kneading $(\mathrm{K})$ and conveying $(\mathrm{C})$ elements, as detailed in Table 1. All formulations were extruded at a screw speed of 50rpm and the temperature profiles employed for ASP and SIM matrices, respectively, are given in Table 2.

\section{Preparation of bilayer dosage forms}

Preparation of the bi-layer co-extrudates was performed using two identical fullyintermeshing co-rotating $10 \mathrm{~mm}$ twin-screw extruders (Rondol ${ }^{\circledR}$ Industries SAS, Strasbourg, 
170 France) connected with an in-house designed co-extrusion die (Figure 1). Co-extrusion was performed with barrel temperature profiles directly transferred from single layer extrusion (Table 2) with the co-extrusion die substituting the original cylindrical die for each extruder. The extruders were fed manually and were operated at screw speeds of $15 \mathrm{rpm}$ (core) and 2 rpm (coat), respectively. Co-extrudates were air-cooled on conveying belt with a measured

175 total diameter of $6.6 \mathrm{~mm}$, a core diameter of 4.6 and coating thickness of $1 \mathrm{~mm}$.

In an attempt to compare the dissolution behaviour of the obtained bilayer co-extrudates with a dosage form prepared via conventional methods, bilayer tablets also were prepared using a hydraulic disc/pellet presser. Approx. $375 \mathrm{mg}$ of an ASP formulation (equating to $75 \mathrm{mg}$ of ASP) was loaded between two stainless steel discs and pressed using a pressure of 7.5 ton for a 3-minute period. The formed ASP tablet was collected and placed in between the two compression discs with approx. 440mg of a SIM formulation (offering equivalent to $20 \mathrm{mg}$ of SIM) placed on top and pressed using a pressure of 7.5 ton for a further 3 minutes. The obtained tablet was a laminar bilayer tablet with a theoretical total weight of $815 \mathrm{mg}$.

185

\section{In-vitro dissolution test}

In-vitro drug release behaviour of ASP and SIM was examined using an USP TYPE II dissolution apparatus tester Copley DIS 8000 (Copley, U.K.). The pH of human GIT increases progressively from the stomach (pH1-3 with an average of 1.8) to the terminal ileum 190 (pH7-8 with an average of 7.5), followed by a sharp decrease to a mean of pH6.5 in the caecum, and then rises progressively again to a final mean of pH 7.0 in the distal colon ${ }^{17-}$ 19. Transit time in the small intestine is often quoted to be 3-4 h. However, in an attempt to treat the distal region where $\mathrm{pH}$ value increases as a separate site, $2 \mathrm{~h}$ was used for pH6.8 to represent the proximal small intestine. Dissolution testing for SIM was therefore 195 carried out as follows:

(I) $\quad 0.1 \mathrm{~N} \mathrm{HCl}(\mathrm{pH} 1.2)$ for two hours;

(II) Medium pH adjusted to 6.8 by addition of $0.2 \mathrm{M} \mathrm{Na}_{3} \mathrm{PO}_{4}$ and the dissolution test was carried out 2 hours (total 4 hours);

(III) $\quad \mathrm{pH}$ was then adjusted to 7.5 using $2 \mathrm{M} \mathrm{NaOH}$ drops and the dissolution continued for 2 hours (total 6 hours); 
(IV) Further $\mathrm{pH}$ adjustment to 6.5 was performed with addition of $1 \mathrm{M} \mathrm{HCl}$ drops and the dissolution test was continued for another 18 hours.

The temperature of the dissolution media was maintained at $37 \pm 0.5^{\circ} \mathrm{C}$ using a paddle stirring speed of 75rpm. During formulation development, pelletised extrudates containing equivalent to $75 \mathrm{mg}$ ASP and $20 \mathrm{mg}$ SIM, respectively, were examined. The co-extruded pellets composed of the most promising ASP and SIM formulations, on the other hand, were examined with equivalent to $50 \mathrm{mg}$ ASP and $25 \mathrm{mg}$ SIM, respectively, in each dissolution vessel. Samples were withdrawn at predetermined time points during the four stages of dissolution. At each time point, a $2 \mathrm{ml}$ aliquot was withdrawn from each dissolution vessel, filtered through a $0.22 \mu \mathrm{m}$ Millex ${ }^{\circledR}$-GS syringe filter and replaced with $2 \mathrm{ml}$ of the corresponding buffer. $1 \mathrm{ml}$ of the filtered aliquot was then diluted with $0.5 \mathrm{ml}$ of acetonitrile (ACN) to prevent recrystallization of SIM during HPLC analysis. For comparison purposes, the dissolution performance of pure SIM powders, Zocor (20mg SIM) and, compressed bilayer tablets were also investigated.

\section{Determination of drug concentration using HPLC.}

Determination of drug concentration was performed using an Agilent infinity series 1220 HPLC (Agilent technology, Germany). All chromatographic analyses were performed in isocratic mode. Two independent methods were developed and validated in order to quantify SIM and ASP, respectively.

Simvastatin lactone and its corresponding open-chain $\beta$-hydroxy acid form were quantified using a C18 Poroshell 300 porous silica column from Agilent ( $300 \AA ̊, 2.1 \times 75 \mathrm{~mm}, 5 \mu \mathrm{m}$ particle size). The mobile phase consisted of a mixture $(42: 58, \mathrm{v} / \mathrm{v})$ of acetonitrile (ACN) and acetate buffer $(12 \mathrm{mM}, \mathrm{pH} 4.5$ adjusted by glacial acetic acid filtered through $0.2 \mu \mathrm{m}$ cellulose nitrate membrane filter). The flow rate was set to $0.28 \mathrm{~mL} / \mathrm{min}$, and the column compartment temperature to $30.0^{\circ} \mathrm{C}$. The injection volume was $3 \mu \mathrm{L}$, and the detection wavelength set to $238 \mathrm{~nm}$. The method was validated and there was no interference from drug components or excipients. 
ASP and its hydrolysis product salicylic acid (SA) were quantified using a $\mathrm{C}^{18}$ Kinetex $^{\oplus}$ column from Phenomenex $(100 \AA, 4.6 \times 150 \mathrm{~mm}, 5 \mu \mathrm{m})$. The mobile phase consisted of a mixture of acetonitrile (ACN) with $0.1 \%$ TFA and phosphate buffer solution $(25 \mathrm{mM}$ adjusted to $\mathrm{pH} 2.0$ using orthophosphoric acid and filtered through $0.2 \mu \mathrm{m}$ cellulose nitrate membrane filter) at 35:65 (v/v) which was filtered and degassed prior to use. The flow rate was set to $1.0 \mathrm{~mL} / \mathrm{min}$, and the column compartment temperature to $30.0^{\circ} \mathrm{C}$. The injection volume was $5 \mu \mathrm{L}$ and the detection wavelength set to $276 \mathrm{~nm}$. The method was validated and showed no interference from simvastatin lactone or its open-chain $\beta$-hydroxy acid.

\section{Raman Spectroscopic analysis}

Raman spectroscopy was performed using a RamanMicro 300 Raman microscope (Perkin Elmer, Windsor, Berkshire, UK) coupled with an Avalon Raman station R3 model AVRS003A spectrometer (Avalon Instrument, Belfast, UK, $785 \mathrm{~nm}$ laser). A magnification of $\mathrm{x} 20$ with a total exposure time of 20s ( $4 s \times 5$ exposures) was used for all samples. Data was collected 245 from 200-3200cm-1 with an automatic baseline correction and 15s photo bleaching. Additionally, drug migration was investigated using Raman mapping. Measurements were performed at a resolution of $2 \mathrm{~cm}^{-1}$ using a x20 objective lens and a total exposure time of $20 \mathrm{~s}$ (5s, x 4 exposures). A pellet cross-section was mapped using a $50 \mu \mathrm{m}$ spacing between points. Raman imaging was performed using Spectrum Image analysis software (R1.6.4.0394)

250 using single wavenumber mode. The wavenumber selected for the APIs were: $1644 \mathrm{~cm}^{-1}$ for SIM and $1039 \mathrm{~cm}^{-1}$ and $932 \mathrm{~cm}^{-1}$ for ASP.

\section{Statistical analysis}

Statistical tests were conducted using GraphPad Prism. A one-way analysis of variance with 255 Tukey's multiple comparison tests was used. The confidence interval was set automatically to 95\%. In all cases, at least six replicates were used for analyses and $p \leq 0.05$ denoted significance. 


\section{Results and Discussion}

260

\section{ASP layer development}

ASP has a relatively poor stability profile being susceptible to ester hydrolysis in the presence of moisture. This results in the formation of two compounds, namely salicylic acid (SA) and acetic acid (AA). The ASP decomposition can be further affected by increasing $\mathrm{pH}$ which 265 facilitates hydrolysis towards completion, and with elevated temperature where salicylic acid is broken down through decarboxylation process to produce phenol and $\mathrm{CO}_{2}{ }^{20}$. Poor stability of ASP, especially if water and/or non-ambient processing is used during manufacture, must be considered. The decomposition of ASP when exposed to high temperatures, a principal concern in this study, has been reported in the literature ${ }^{21,22}$. It was therefore the main focus,

270 in the design and process of an IR ASP formulation, to prevent ASP decomposition and SA formation..

Herein, the two main criteria imposed for carrier selection for an ASP layer were (i) the ability of the carrier to offer compendial-acceptable immediate ASP release, and (ii) the ability to process the formulation without inducing ASP thermal degradation. Pre-formulation 275 characterisation of ASP using thermogravimetric analysis showed that ASP started to show significant decomposition close to its melting point (onset of melting at approx. $142^{\circ} \mathrm{C}$ whilst peak at $150^{\circ} \mathrm{C}$, thermogram not shown). It is therefore abundantly clear that the processing temperature selected for HME should be strictly controlled and ideally well below $142^{\circ} \mathrm{C}$ to minimise the risk of ASP degradation. Taking this into consideration, EPO, SOL and VA64 were 280 selected for preliminary investigation. The EPO-ASP binary mixture was not extrudable below the set criteria and therefore plasticiser was incorporated. It was suggested in a previous publication that the addition of polyethylene glycol (PEG) could significantly reduce the extrusion torque and consequently reduce the melt zone temperature setting for EPO based matrices ${ }^{22}$. For PVP-VA64 matrices, plasticisers were mainly used to improve extrudates

285 flexibility and hence downstream processability. A citrate ester plasticiser, triethyl citrate (TEC), in addition to PEG, was also studied for its suitability in such cases owing to its frequent use in polymers with vinyl groups. For extrudates consisted of Soluplus, on the other hand, Lutrol F68 (a Polyoxyethylene-polyoxypropylene block copolymer) was utilised as a 
dissolution modifier since extruded SOL matrices are well-known for their compendial290 unsatisfactory dissolution performance.

The extruded ASP matrices were examined for free SA content as well as the actual drug loading in each formulation where both recovered ASP and SA were taken into account (Table 3). It is clearly shown that formulations based on SOL and VA64 all yielded excellent match between theoretical and measured drug loadings with compendial-acceptable levels of SA 295 content ( $<3 \%$ of the labelled ASP amount). Formulations based on EPO, on the other hand, all resulted in high free SA content and moreover, unaccounted drug loss. Such results may be indicative of ASP degradation pathways other than hydrolysis, in this case most probably, thermal decomposition. It is worth mentioning that the equal-weight blending of VA64 with EPO (formulations ASP 4-6) was originally intended to decrease the required processing 300 temperature. Interestingly, as shown by the measured drug loading values (Table 3), such practice incidentally supports the aforementioned thermal decomposition hypothesis as the recovered drug content increased with decreasing processing temperature.

The SOL and VA64 based ASP formulations were subjected to drug release study using simulated blank gastric fluid ( $\mathrm{pH} 1.2)$ and the dissolution profiles are illustrated in Figure 2. It 305 was evident that the ASP-SOL matrice (formulations ASP 1 \& 2) exhibited statistically similar release profiles, despite the addition of Lutrol F68 to ASP 2 as a dissolution modifier. The rate of drug release for neither ASP-SOL formulations was compendial satisfactory (at least 75\% release within the first $45 \mathrm{~min}$ according to compendial methods) ${ }^{23,24}$, where only approx. $20 \%$ drug was released after 45 minutes (Table 3), and should fail as immediate release 310 platforms. By comparison, formulations manufactured using VA64 (ASP 7 - ASP 11) all passed the compendial requirement for dissolution rate as an immediate release formulation, with ASP 7 and ASP 9 releasing $94.67 \pm 3.97 \%$ and $94.08 \pm 1.56 \%$ aspirin, respectively within $45 \mathrm{~min}$ and reaching complete release at $90 \mathrm{~min}$, both qualifying as the most successful ASP formulation. ASP 7, however, was suboptimal due to flexibility issues after cooled to ambient

315 temperature. The lack of flexibility is not only problematic during downstream secondary processing such as cutting/pelletizing, but can also cause surface defects when used as an exterior coating in multilayer co-extrusion. ASP 9, on the other hand, exhibited significantly improved flexibility therefore represented the best candidate to carry forward to bilayer coextrudate studies. 


\section{SIM layer development}

As with Aspirin, pre-formulation studies involving solid state characterisation (DSC and TGA) of SIM was performed. Thermogravimetric analysis showed that SIM started to degrade at a relatively high temperature, approximately $240^{\circ} \mathrm{C}$ (data not shown). On the other hand, DSC 325 thermograms showed that $\mathrm{SIM}$ melted at $145^{\circ} \mathrm{C}$ and formed an amorphous solid with a glass transition at approximately $36^{\circ} \mathrm{C}$ if quench cooled from its melt (Figure 3). The large gap (around $100^{\circ} \mathrm{C}$ ) between SIM melting and its onset of degradation provided a extensive processing temperature window without inducing SIM thermal degradation. The ultimate goal of formulating SIM was to delay its release until it reaches specific sites of the GIT (distal 330 small intestine and proximal colon) at which the expression of the oxidative enzymes, CYP450 $3 \mathrm{~A} 4$, are at a minimum ${ }^{25}$. Delaying SIM release is expected to result in an improvement in the pharmacokinetic activity of the drug as a consequence of the reduced metabolism by localized oxidative enzymes. Additionally, SIM formulation should be enabling and improve drug solubility, which in turn, might synergistically improve its bioavailability. There are a number

335 of different polymers commonly used to target drugs to specific regions of the GIT (Table 4).

Initial studies using a broad range of enteric polymers confirmed that HPMC-AS was the most appropriate polymer for formulation. Eudgrait S100 was difficult to extrude and released drug much too slowly to be of benefit in this study. HPMC-AS was carried forward and a number of different polymer combinations were extruded based upon this base polymer (Table 5).

340 Melt-extruded matrices showed excellent gastric and proximal small intestinal resistance in the in-vitro simulated fluids (with less than $10 \%$ drug release in $\mathrm{pH} 1.2$ and $\mathrm{pH} 6.8$ media (Figure 4). It was found that factors such as excipient blend ratio, plasticizer loading, and addition of antioxidant, could significantly influence the release kinetics.

The effect of drug loading (Figure 4a) on the release behaviour of extruded formulations was 345 tested at two different drug loadings (5 and 20\% w/w). Dissolution testing revealed that the higher the drug loading, the lower the extent of release. This can be attributed to the fact that the concentration of the polymers, which are expected to inhibit the precipitation of SIM, is lower at high drug loading and hence decreased potency to remain supersaturated under non-sink conditions. 
350 In a similar manner, the amount of TEC added to the formulation inversely affected the extent of SIM release (Figure $4 \mathrm{~b}$ ) which can be attributed to the fact that the concentration of the polymers is lower at higher TEC concentrations. However, increased plasticizer content noticeably improved extrudate flexibility. All investigated formulations showed multi-stage, $\mathrm{pH}$ dependent dissolution behaviour. In all cases, although the delivery platforms released 355 drug that mirrored the $\mathrm{pH}$ step change, the release of drug was incomplete in the final phase (pH 6.5). Thus, Eudragit L-100-55 was incorporated as a polymer that has a lower pH solubility threshold when compared to both HPMCAS-HF and L-100. A formulation based on a higher ratio of HPMCAS-HF compared to L-100 and L-100-55 (Figure 4c) showed a higher extent of release when compared to those composed of an equal ratio of the three polymers. The 360 difference in the extent of SIM released was only observed at stage III and stage IV of the dissolution experiment. At these stages, the $\mathrm{pH}$ of the media is higher than or equal to the $\mathrm{pH}$ value at which HPMCAS-HF begins to dissolve. Thus, the higher the ratio of HPMCAS-HF the higher the extent of release. The presence of HPMCAS-HF might have also played an important role in retarding the precipitation of SIM as described previously. Therefore, the 365 higher the ratio, the higher the extent of inhibition and hence higher the extent of SIM release. The dissolution behaviour of the extruded formulation was further improved by the addition of TPGS as a dissolution modifier. The incorporation of TPGS, a water-soluble vitamin E derivative, played two important roles: (I) to prevent the oxidation reaction of the carboxylic acid groups in HPMCAS-HF during extrusion and (II) owing to the amphiphilic nature of the 370 compound, it was found that SIM release was significantly improved (when compared to those without TPGS.

Based on these preliminary investigations whereby binary polymeric combinations were used as a platform to manufacture tailored delayed release drug delivery systems, a blend of HPMCAS-HF/L-100/L100-55 was employed as a matrix for SIM dispersion. The blend was 375 loaded with $5 \% \mathrm{w} / \mathrm{w}$ of SIM and plasticized with TEC in order to improve processability. The matrix was able to retard drug release at low $\mathrm{pH}$ (1.2) and started to release SIM upon changing $\mathrm{pH}$ to 6.8. This delivery platform was able to maintain the release of SIM upon further change in media $\mathrm{pH}$ to 7.5 with further release observed when media $\mathrm{pH}$ reduced to 6.5. Interestingly, the solubility of SIM was improved (approximately two-fold 380 increase) when compared to pure SIM. Despite the improvement in the dissolution behaviour of the extruded formulation following matrix development, the incomplete release 
of SIM over the 24-hour period was considered a major drawback of the formulation. Therefore, to drive the release to completion within the 24-hour window, the incorporation of a lower grade of HPMCAS polymer which had lower $\mathrm{pH}$ solubility threshold was considered. 385 Subsequently, HPMCAS-HF was substituted with a lower grade HPMCAS-MF which has a lower threshold of $\mathrm{pH}$ solubility $(0.5 \mathrm{pH}$ units than $\mathrm{HF})$. Formulations based on different ratios of HPMCAS-HF:HPMCAS-MF were extruded using the conditions described previously. Solid state characterisation of the obtained extrudates revealed a single glass transition temperature at $53^{\circ} \mathrm{C}$ which is an intermediate temperature between that of the drug and the 390 excipient mixture, indicative of an amorphous miscible system (Figure 5). Amorphization of SIM in these formulations was also evident with complete loss of crystalline characteristics (halo like PXRD pattern, Figure 6) when compared with the physical mixture of the formulations. Figure 7 depicts the dissolution behaviour of the formulations based on $100 \%$ HPMCAS-HF, 50:50 HPMCAS-HF: HPMCAS-MF and 100\% HPMCAS-MF. Substituting 50\% of

395 HPMCAS-HF resulted in no significant improvement in both dissolution rate and extent in simulated ileum fluid (Figure 7, pH 7.5) which can be explained by the fact that neither of the polymers is dominant and hence there was no impact upon release of the drug. As the $\mathrm{pH}$ of the dissolution was altered to 6.5, a significant difference in the extent of dissolution was observed which can be attributed to the presence of HPMCAS-MF which has a pH threshold 400 below the $\mathrm{pH}$ of the media. Despite the improvement in SIM release, complete release was not achieved for either formulation. Complete substitution of HF grade with the MF grade, interestingly, resulted in a significant improvement in SIM release in the dissolution media. This was particularly evident in regions mimicking the Gl fluid of the duodenum-proximal colon, with greater release at $\mathrm{pH} 7.5$, representing the ileum/proximal colonic region of the 405 GIT. The ability of this combination of polymer to retard the release at low $\mathrm{pH}$ and to completely release SIM at high $\mathrm{pH}$ is attributed to the presence of polymers that have relatively high $\mathrm{pH}$ threshold to bypass the low $\mathrm{pH}$ media of the stomach but low enough to release SIM as the media $\mathrm{pH}$ increases. The $\mathrm{pH}$ of the buffer at the last three stages of the dissolution test was above the $\mathrm{pH}$-solubility threshold of all the polymers included in the 410 formulation thus facilitating matrix dissolution and hence a significant improvement in SIM release. The ability of this formulation to behave in a similar manner when tested in-vivo is highly desirable as the oxidative enzymes associated with the degradation of SIM are highly concentrated in the proximal part of the Gl tract and is known to be less expressed at the 
distal part of the Gl tract. Based on the desirable dissolution behaviour obtained with 415 formulation SIM 6, it was later used as the core layer of the co-extruded bi-layer release platform.

\section{Preparation of multilayer drug delivery system based on optimised ASP and SIM formulations.}

\section{Co-extrusion}

Formulations of both ASP (ASP 9) and SIM (SIM 6) were manually fed into the extruders to manufacture co-extrudates that combine two different drug delivery platforms. The resulted co-extrudates (Figure 8) showed a clear formation of the coat-and-core structure with a core of $6.6 \mathrm{~mm}$ diameter covered by a $1 \mathrm{~mm}$ thick coat.

425 Obtained co-extrudates were subsequently cut into pellets with a length of $6 \mathrm{~mm}$ (equal to the overall diameter of the co-extrudates) and were used for dissolution testing. The drug contents in the pelletised bilayer co-extrudates were determined. Figure 9 illustrates the dissolution behaviour of the obtained co-extrudates. Both layers showed a dissolution behaviour matching their corresponding monolithic extrudates. More specifically, the coat 430 layer released $90 \%$ of ASP in 45 minutes and completely released ASP within the first two hours. On the other hand, the core layer desirably retarded the release of SIM in the first two hours (average residence time in the stomach) and started to release SIM upon increasing the $\mathrm{pH}$ of the dissolution media to a $\mathrm{pH}$ mimicking the hostile environment in the middle part of the small intestine (jejunum). Further release of SIM was observed with increasing the $\mathrm{pH}$ of 435 the dissolution media to 7.5 at which $>80 \%$ of SIM was released.

Spectroscopic analysis using Raman spectroscopy (Raman mapping) showed a clear separation between the core and coat layer (Figure 10). The spectra from both the core and the coat layers showed good agreement with those of the monolithic systems. The coat layer spectrum (Figure 11) showed a peak at $1039 \mathrm{~cm}^{-1}$ corresponding to ASP with complete

440 absence of the peaks associated with SA confirmed the stability of ASP during co-extrusion. With respect to the core layer, the characteristic peak of SIM at $1646 \mathrm{~cm}^{-1}$ was shifted to 1644 $\mathrm{cm}^{-1}$ in the spectrum of the core layer (Figure 11) suggesting an interaction between SIM and the polymeric mixture of the core layer. Tracking ASP and SIM migration (using single 
wavenumber analysis) during co-extrusion showed that both SIM and ASP was distributed in 445 the core/coat layers with no sign of migration, immediately following extrusion. The red spots found in the core layers upon tracking ASP migration using a wavenumber of $1039 \mathrm{~cm}^{-1}$ was attributed to overlapping between the spectra of the core with that of the coat at this wavenumber due to the noise in the baseline. However, using another distinct wavenumber (932 $\mathrm{cm}^{-1}$, limited overlap with the coat spectrum) to track ASP distribution, removed this 450 issue (Figure 10).

\section{Multilayer tablet}

In an attempt to compare the dissolution behaviour of multilayer drug delivery systems manufactured using advanced and conventional manufacturing techniques, optimised ASP and SIM formulations (ASP 9 and SIM 6, respectively) were also manufactured into a multilayer tablet using standard compression. The obtained extrudates were milled and compressed into bilayer tablets as described previously. It is worth noting that the dissolution behaviour of the co-extruded pellets showed no significant difference when compared to milled extrudates. Despite this, the in-vitro dissolution behaviour of the bi-layer tablet (Figure 460 12) was significantly different to the co-extrudate. In particular, ASP in the immediate release layer achieved 40 percent ASP release within the first 45 minutes, whereas co-extrudate ASP release levels met compendial standards. This may be due to variations in the disintegration of the ASP layer, as the result of secondary processing (compression) and change of layer thickness. The fact that the ASP layer requires burst release as an IR platform emphasises the 465 role of disintegration. Interestingly, there was no difference in the release of simvastatin in the extruded matrix and the bilayer tablet.

\section{Conclusion}

In this study, HME was successfully employed to manufacture two different drug delivery 470 systems exhibiting immediate and delayed release of ASP and SIM, respectively. The data obtained shows the importance of using a combination of polymers to attain better control of a site-specific drug release. A blend of the anionic polymers was able to retard SIM release in the low-pH media (pH 1.2) and release SIM upon transition to higher $\mathrm{pH}$ media (>6.8). 
Manipulation of formulation components such as plasticizer concentration, drug loading and 475 polymer ratio clearly impact the release kinetics and the extent of SIM release. Substituting high $\mathrm{pH}$ threshold polymers with low $\mathrm{pH}$ threshold polymers was associated with a higher extent of release. Manufacture of multilayer drug delivery systems was successfully performed using two different manufacturing techniques (co-extrusion and conventional compression). The release of ASP was significantly different between these two dosage forms, 480 with the co-extruded bi-layer drug delivery systems outperforming the bi-layer tablet. It may be interesting to examine the performance of multilayer mini-tablets (exhibiting a greater surface area) using conventional manufacturing methods and compare to co-extruded pellets. As a proof of concept, this paper has shown potential of Hot Melt Co-extrusion as a viable continuous manufacturing method capable of producing advanced bi-layer 485 combination drug delivery systems for CVD management. 


\section{References}

490 (1) Bhatnagar, P.; Wickramasinghe, K.; Williams, J.; Rayner, M.; Townsend, N. The Epidemiology of Cardiovascular Disease in the UK 2014. 2015, 1-8.

(2) WHO | Cardiovascular Diseases (CVDs). WHO 2017.

(3) Nelson, R. H. Hyperlipidemia as a Risk Factor for Cardiovascular Disease. Prim. Care Clin. Off. Pract. 2013, 40 (1), 195-211.

495 (4) Singh, K.; Salam, A.; Devarajan, R.; Patel, A.; Prabhakaran, D. Polypill (Fixed-Dose Combination) in the Prevention of Cardiovascular Disease: Rationale and Clinical Data. Clin. Investig. (Lond). 2012, 2 (12), 1213-1229.

(5) Taylor, F.; Huffman, M. D.; Macedo, A. F.; Moore, T. H.; Burke, M.; Davey Smith, G.; Ward, K.; Ebrahim, S. Statins for the Primary Prevention of Cardiovascular Disease. In $500 \quad$ Cochrane Database of Systematic Reviews; Huffman, M. D., Ed.; John Wiley \& Sons, Ltd: Chichester, UK, 2013; p CD004816.

(6) Whalen, K.; Finkel, R. (Richard S. .; Panavelil, T. A. Lippincott Illustrated Reviews: Pharmacology; 2014.

(7) Plakogiannis, R.; Cohen, H. Optimal Low-Density Lipoprotein Cholesterol Lowering 505 Morning versus Evening Statin Administration. Ann. Pharmacother. 2007, 41 (1), 106110.

(8) Prescribing and Primary Care Team; Health and Social Care Information Centre. Prescription Cost Analysis England 2012: Prescription Items Dispensed in the Community in England and Listed Alphabetically within Chemical Entity by Therapeutic $510 \quad$ Class; 2013.

(9) Jiang, T.; Han, N.; Zhao, B.; Xie, Y.; Wang, S. Enhanced Dissolution Rate and Oral Bioavailability of Simvastatin Nanocrystal Prepared by Sonoprecipitation. Drug Dev. Ind. Pharm. 2012, 38 (10), 1230-1239.

(10) Tubic-Grozdanis, M.; Hilfinger, J. M.; Amidon, G. L.; Kim, J. S.; Kijek, P.; Staubach, P.; Langguth, P. Pharmacokinetics of the CYP 3A Substrate Simvastatin Following Administration of Delayed versus Immediate Release Oral Dosage Forms. Pharm. Res. 2008, 25 (7), 1591-1600.

(11) Wilson, M.; Williams, M. A.; Jones, D. S.; Andrews, G. P. Hot-Melt Extrusion Technology and Pharmaceutical Application. Ther. Deliv. 2012, 3 (6), 787-797. 
520 (12) Sarode, A. L.; Sandhu, H.; Shah, N.; Malick, W.; Zia, H. Hot Melt Extrusion (HME) for Amorphous Solid Dispersions: Predictive Tools for Processing and Impact of DrugPolymer Interactions on Supersaturation. Eur. J. Pharm. Sci. 2013, 48 (3), 371-384.

(13) Repka, M. A.; Majumdar, S.; Battu, S. K.; Srirangam, R.; Upadhye, S. B. Applications of Hot-Melt Extrusion for Drug Delivery . Expert Opin. Drug Deliv. 2008, 5 (12), 13571376.

(14) Lang, B.; McGinity, J. W.; Williams, R. O. Hot-Melt Extrusion - Basic Principles and Pharmaceutical Applications. Drug Dev. Ind. Pharm. 2014, 40 (9), 1133-1155.

(15) Dierickx, L.; Saerens, L.; Almeida, A.; De Beer, T.; Remon, J. P.; Vervaet, C. Co-Extrusion as Manufacturing Technique for Fixed-Dose Combination Mini-Matrices. Eur. J. Pharm. Biopharm. 2012, 81, 683-689.

(16) Vynckier, A. K.; Dierickx, L.; Saerens, L.; Voorspoels, J.; Gonnissen, Y.; De Beer, T. HotMelt Co-Extrusion for the Production of Fixed-Dose Combination Products with a Controlled Release Ethylcellulose Matrix Core. Int. J. Pharm. 2014, 464, 65-74.

(17) Dressman, J. B. Comparison of Canine and Human Gastrointestinal Physiology. Pharm. Res. 1986, 3 (3), 123-131.

(18) Evans, D. F.; Pye, G.; Bramley, R.; Clark, a G.; Dyson, T. J.; Hardcastle, J. D. Measurement of Gastrointestinal PH Profiles in Normal Ambulant Human Subjects. Gut 1988, 29, 1035-1041.

(19) Dressman, J. B.; Krämer, J. Dissolution Testing Pharmaceutical Dissolution Testing; 540 2005.

(20) Bakar, S. K.; Niazi, S. Stability of Aspirin in Different Media. J. Pharm. Sci. 1983, 72 (9), 1024-1026.

(21) BOGDAN TIPA, ADRIANA FULIAS, ELEONORA MARIAN, D. T. Thermal Behaviour of Acetylsalicylic Acid - Active Substance and Tablets Kinetic Study under Non-Isothermal 545 Conditions. Rev. Chim. -Bucharest 2009, 60 (4), 419-423.

(22) Dierickx, L.; Van Snick, B.; Monteyne, T.; De Beer, T.; Remon, J. P.; Vervaet, C. CoExtruded Solid Solutions as Immediate Release Fixed-Dose Combinations. Eur. J. Pharm. Biopharm. 2014, 88 (2), 502-509.

(23) Aulton, M.; Taylor, K. Aulton's Pharmaceuticals, Fourth.; Elsevier, 2013.

550 (24) British Pharmacopoeia Commission. British Pharmacopoeia; British Pharmacopoeia Commission: London, England: The Stationery Office, 2012. 
(25) Paine, M. F.; Khalighi, M.; Fisher, J. M.; Shen, D. D.; Kunze, K. L.; Marsh, C. L.; Perkins, J. D.; Thummel, K. E.; Chemistry, M.; Clm, S. Characterization of Interintestinal and Intraintestinal Variations in Human CYP3A-Dependent Metabolism 1.

555 (26) Friesen, D. T.; Shanker, R.; Crew, M.; Smithey, D. T.; Curatolo, W. J.; Nightingale, J. A. S. Hydroxypropyl Methylcellulose Acetate Succinate-Based Spray-Dried Dispersions: An Overview . Mol. Pharm. 2008, 5 (6), 1003-1019.

(27) Patra, C. N.; Priya, R.; Swain, S.; Kumar Jena, G.; Panigrahi, K. C.; Ghose, D. Pharmaceutical Significance of Eudragit: A Review. Futur. J. Pharm. Sci. 2017, 3 (1), 3345.

565

570 


\section{List of Figures}

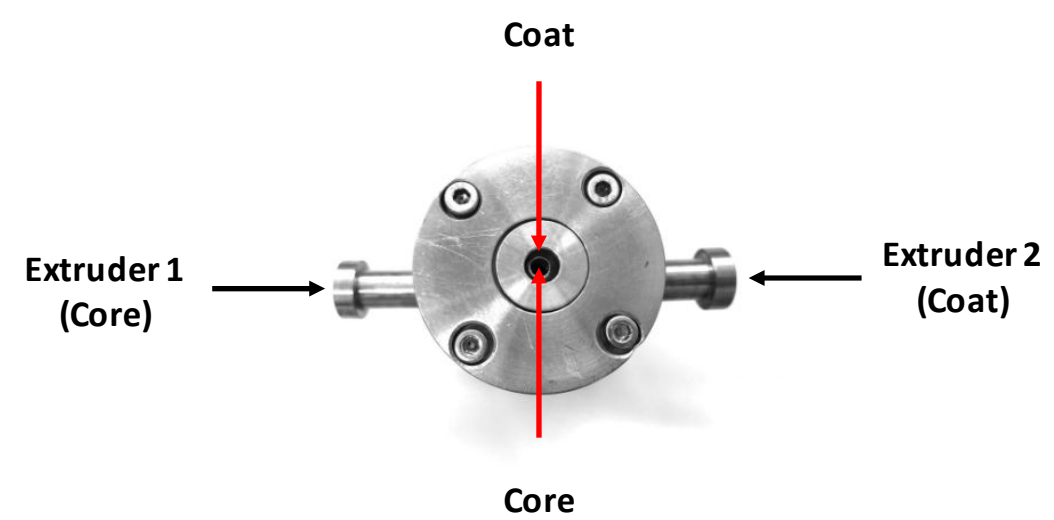

585 Figure 1. In-house designed co-extrusion die used in the preparation of concentred bi-layer co-extrudates. 


\section{0}

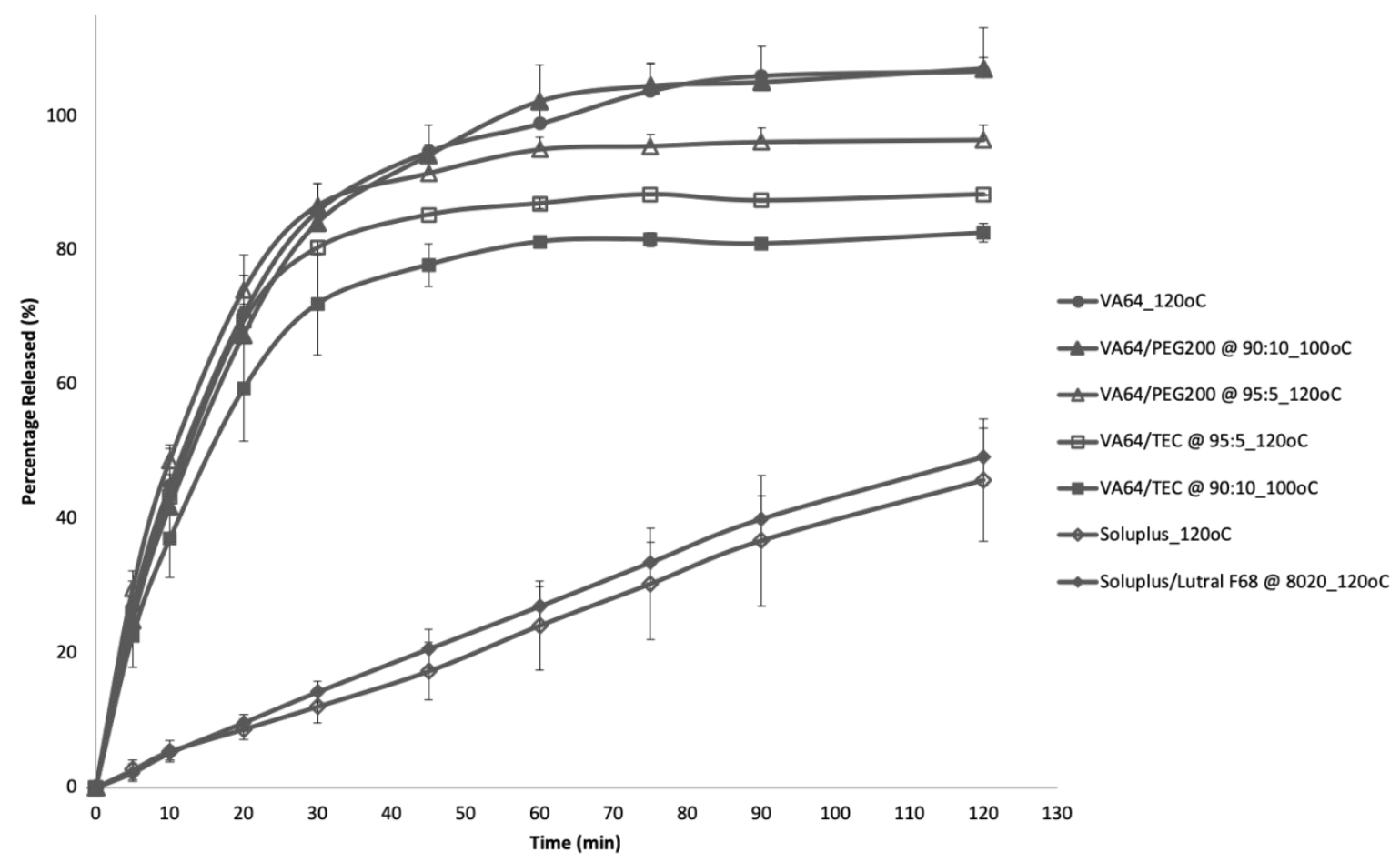

Figure 2 Dissolution profiles of ASP extrudates based on SOL, EPO and VA64, respectively, as polymeric carriers. Dissolution testing was performed in $0.1 \mathrm{~N} \mathrm{HCl}$. ( \pm S.D., $n=3$ ) 
1

2

4

4
5

6

7

8

9

10

11

12

13

14

15

16

17

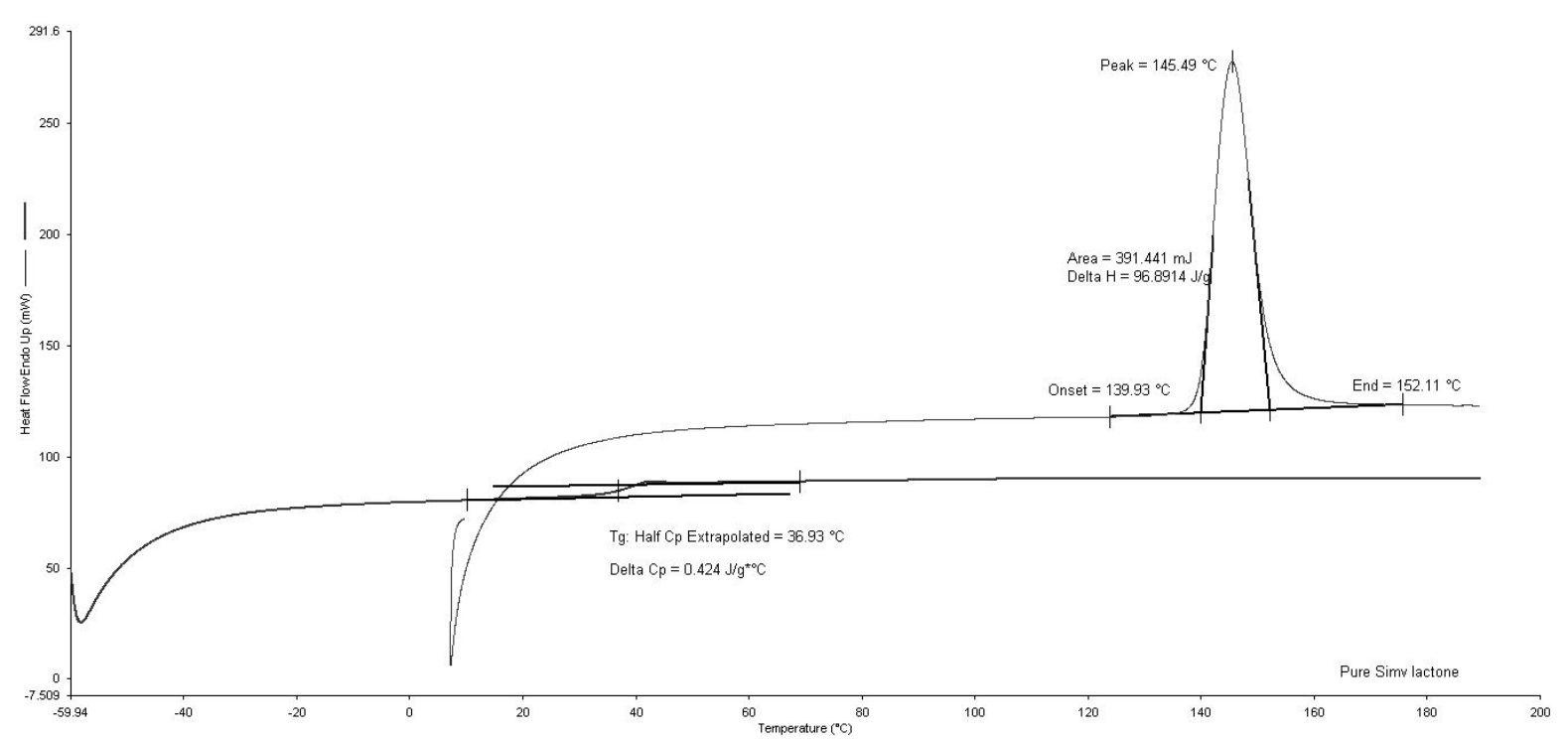

Figure 3. DSC thermogram for SIM obtained by sequential heat/cool/heat procedure using high speed DSC. 


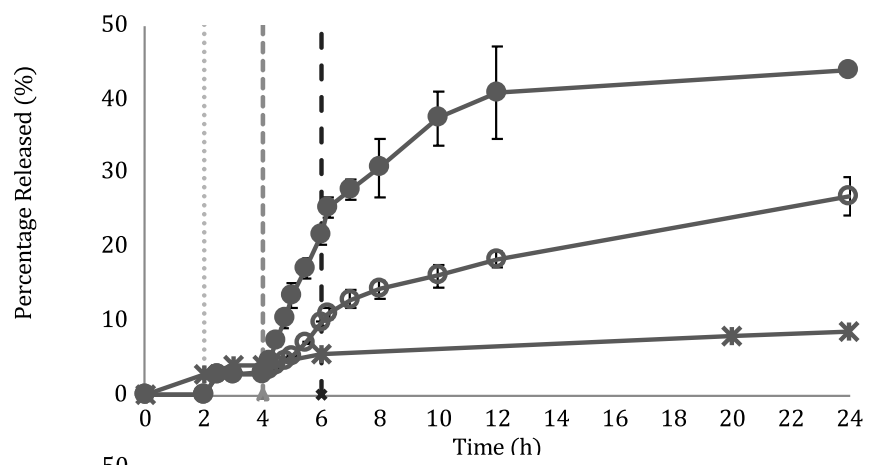

(a)

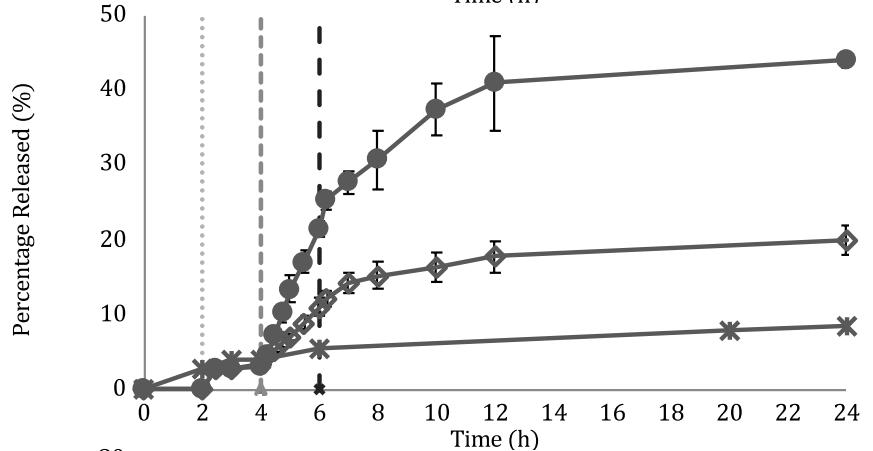

(b)

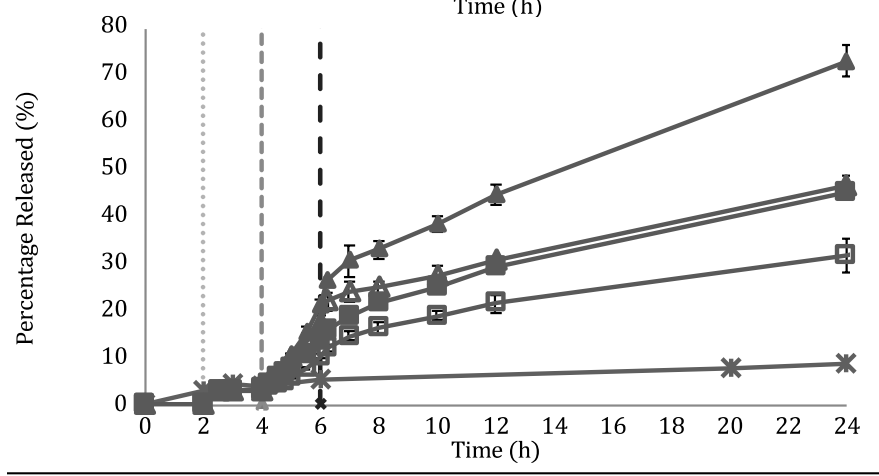

(c)

Figure 4 In-vitro dissolution profiles of melt-extruded SIM formulations showing (a) the influence of SIM loading, (b) TEC content and, (c) blend ratio amongst three anionic matrix polymers as well as the addition of an antioxidant TPGS, respectively. 


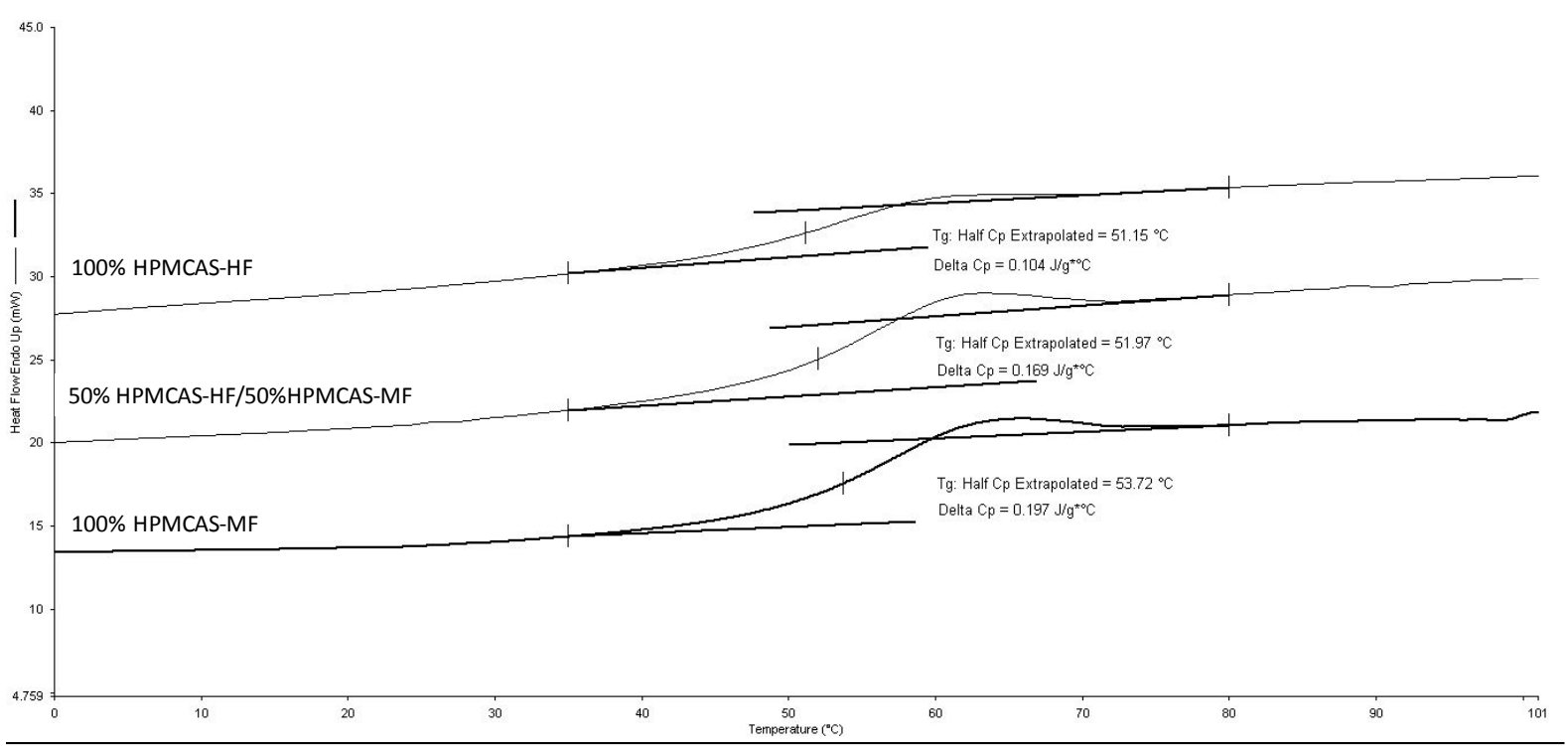

Figure 5: DSC thermogram for SIM formulations based on different ratios of HPMCAS-HF and HPMCAS-MF obtained using Hyper DSC. A glass transition temperature event was evident during heating at $200^{\circ} \mathrm{C} / \mathrm{min}$ from ambient to $100^{\circ} \mathrm{C}$. 


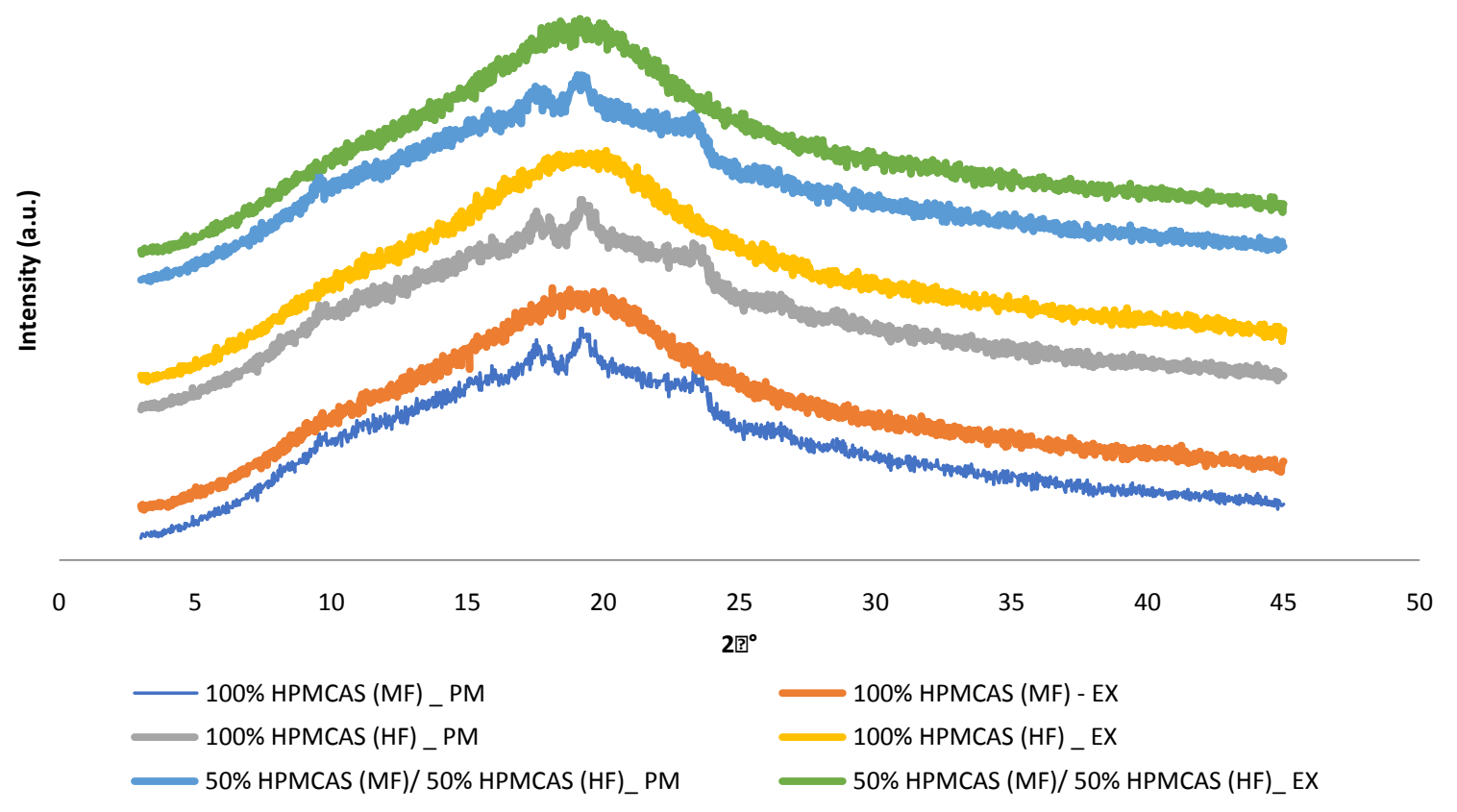

Figure 6: PXRD patterns for the physical mixtures and extruded matrices of the of the formulation based on different ratios of HPMCAS-HF and HPMCAS-MF. Measurements were performed between 3-45 $2 \theta^{\circ}$ at scan speed of $2.0 \% \mathrm{~min}$. 


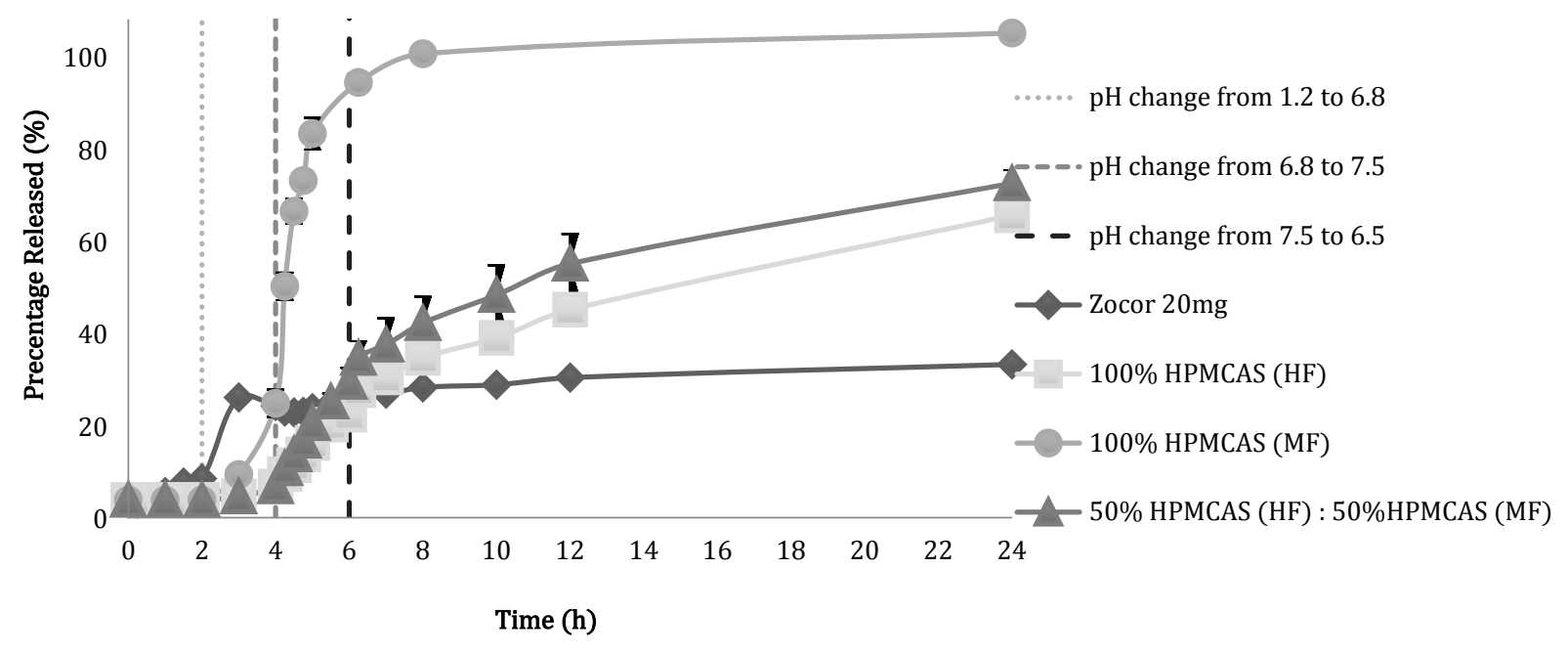

Figure 7: Dissolution behaviour of extrudates shows the effect of changing HPMCAS grades on the extent of SIM release. Values represent the average $\pm S D(N=3)$. 
630 Figure 8: Representative micro-photos of the co-extrudates produced using the prompted formulations showing the diameter of the co-extrudates and the core layer. 


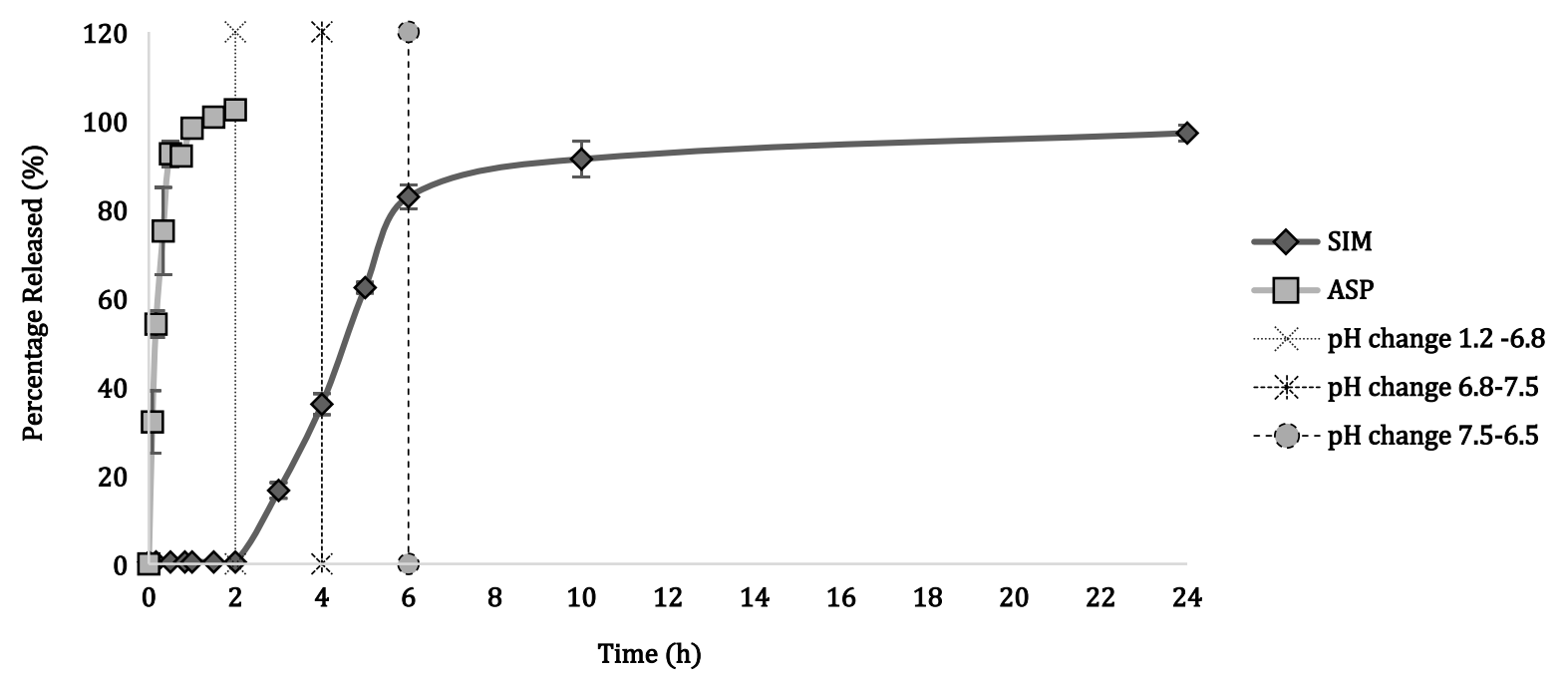

635

Figure 9: Dissolution behaviour of the co-extrudates combining an immediate release ASP and a delayed release SIM. Values represent the average $\pm S D(N=3)$. 


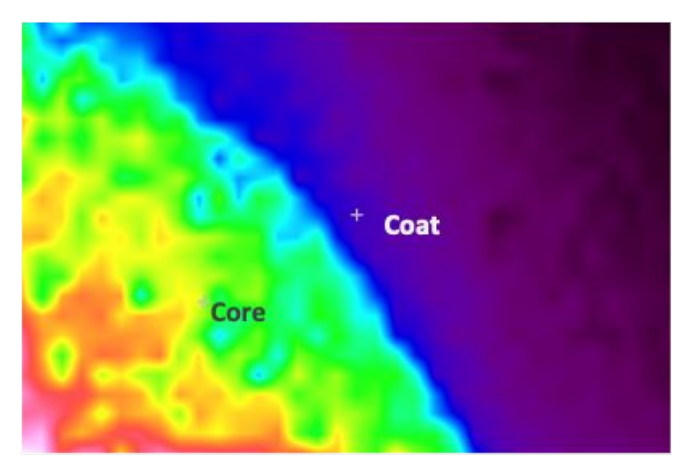

Average intensity

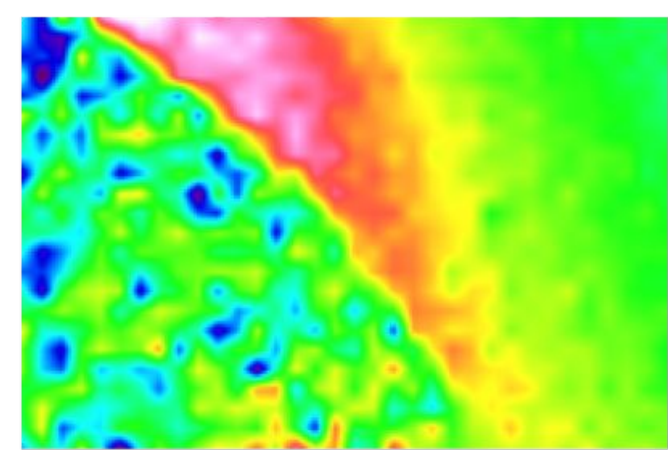

Coat $\left(1039 \mathrm{~cm}^{-1}\right)$

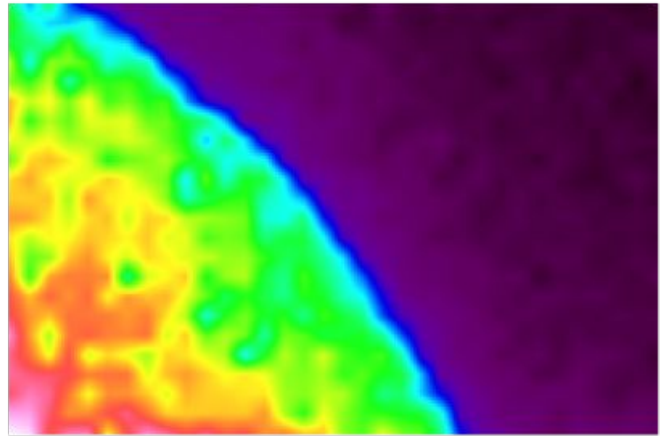

Core $\left(1644 \mathrm{~cm}^{-1}\right)$

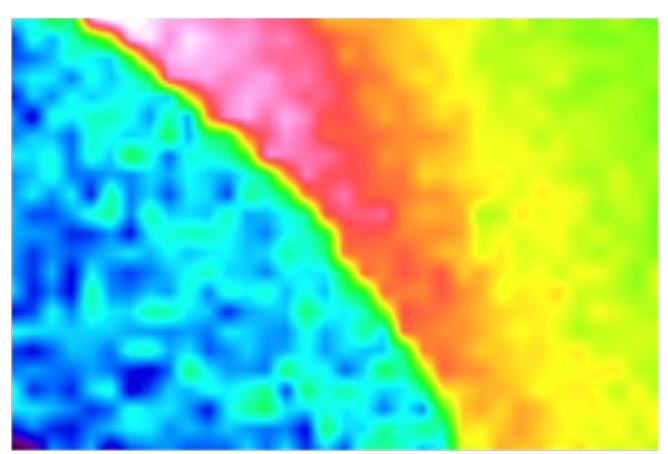

Coat $\left(932 \mathrm{~cm}^{-1}\right)$

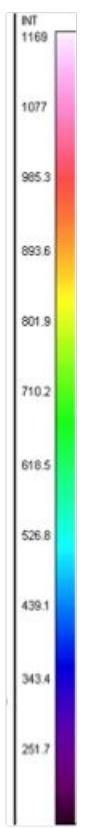

Figure 10 False colour map of the co-extrudates showing the clear separation between the core and the coat layers. Average intensity (top left), SIM distribution (top right), ASP distribution (1039 $\mathrm{cm}^{-1}$, bottom left) and ASP distribution (932 cm $\mathrm{cm}^{-1}$, bottom right). Measurements were performed at resolution of $2 \mathrm{~cm}^{-1}$ and total exposure time of $20 \mathrm{~s} /$ point and using a co-extrudate immediately after production. 


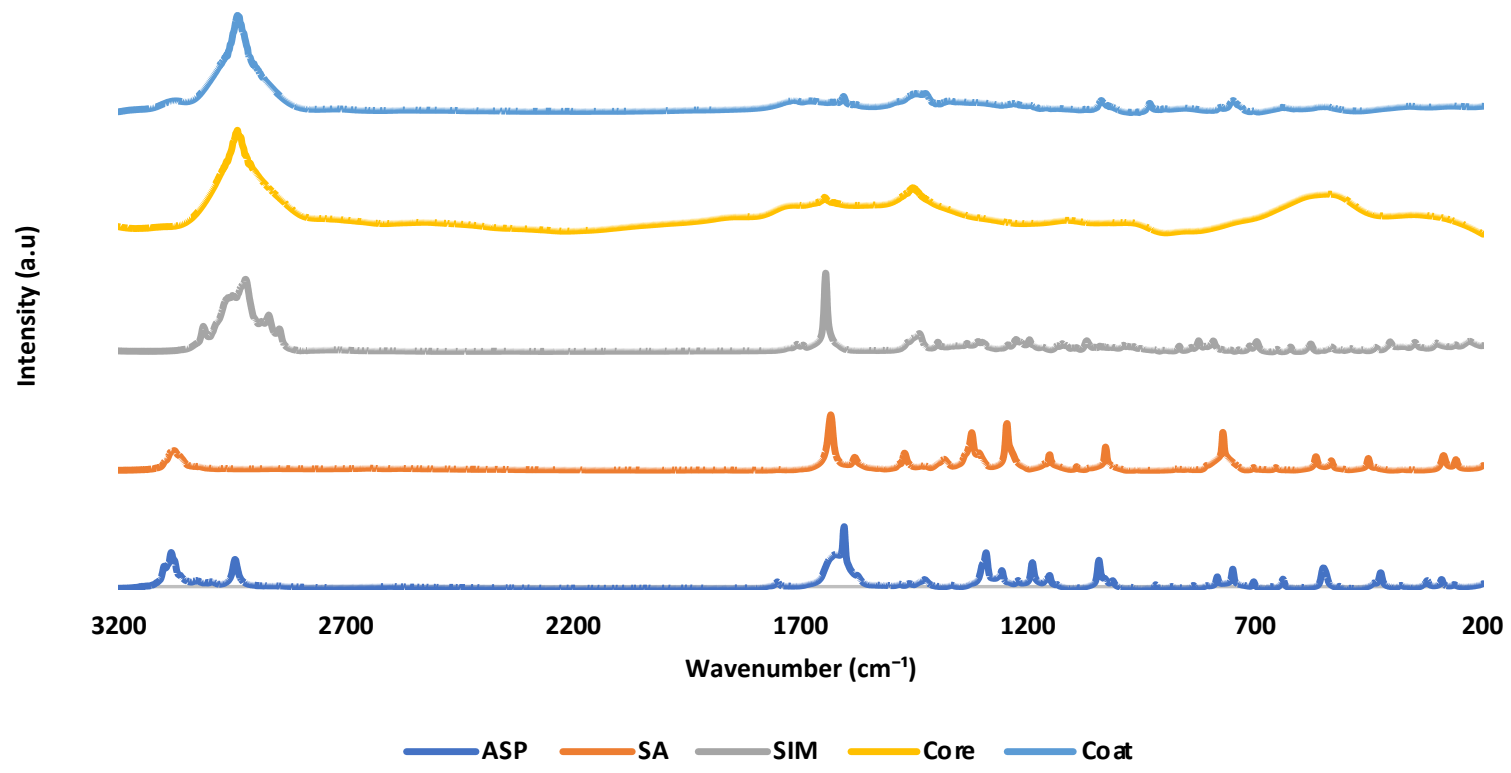

655 Figure 11 Raman spectra of (from bottom to top): ASP (blue), SA (orange), SIM (grey), core layer (yellow) and the coat layer (light blue). Measurement were performed at resolution of $2 \mathrm{~cm}^{-1}$ and total exposure time of $20 \mathrm{~s}$. 
2

4

5

6

7

8

9

10

11

12

13

14

15

16

17

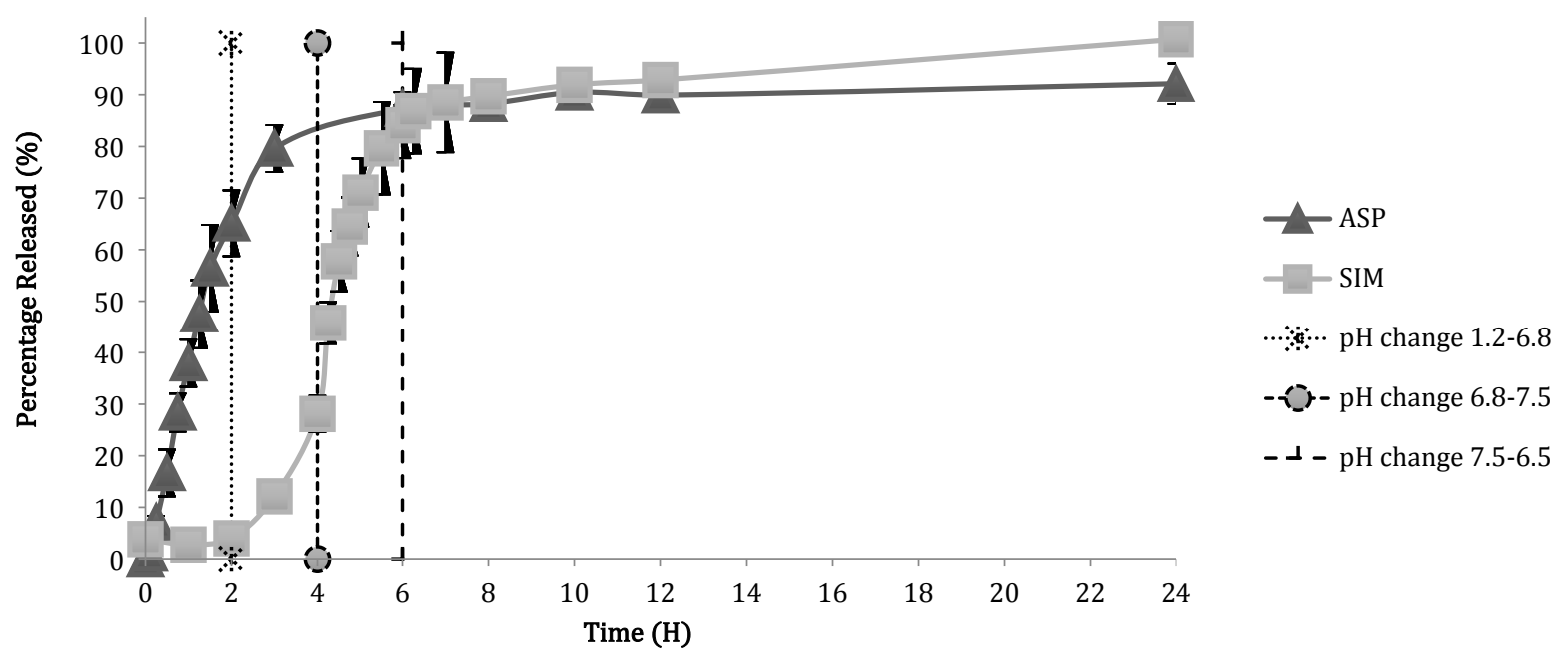

Figure 12: Dissolution behaviour of bi-layer tablet combining an immediate release ASP and a delayed release 660 SIM. Values represent the average $\pm S D(N=3)$. 
List of tables

Table 1: Screw configuration used for extrusion processing of simvastatin and aspirin optimized formulations.

\begin{tabular}{cl|ll}
\hline \multicolumn{2}{c|}{ SIMVASTATIN } & \multicolumn{2}{c}{ ASPIRIN } \\
No. of Elements & Element Type & No. of Elements & Element Type \\
\hline 5 & Forward conveying & 8 & Forward conveying \\
2 & $60^{\circ}$ kneading & 1 & $60^{\circ}$ kneading \\
2 & $90^{\circ}$ kneading & 1 & $90^{\circ}$ kneading \\
1 & $60^{\circ}$ kneading & 1 & $60^{\circ}$ kneading \\
2 & Forward conveying & 3 & Forward conveying \\
1 & $60^{\circ}$ kneading & 1 & $60^{\circ}$ kneading \\
1 & $90^{\circ}$ kneading & 1 & $90^{\circ}$ kneading \\
1 & $60^{\circ}$ kneading & 3 & Forward conveying \\
4 & Forward conveying & 1 & End unit \\
1 & End unit & & Screw tip \\
& Screw tip & & \\
\hline
\end{tabular}

685 
Table 2: Barrel temperatures for the extruders used to manufacture the core (SIM) and the coat (ASP) layers.

\begin{tabular}{lccccc}
\hline & Zone $1\left({ }^{\circ} \mathrm{C}\right)$ & Zone $2\left({ }^{\circ} \mathrm{C}\right)$ & Zone 3 $\left({ }^{\circ} \mathrm{C}\right)$ & Zone $4\left({ }^{\circ} \mathrm{C}\right)$ & Die $\left({ }^{\circ} \mathrm{C}\right)$ \\
\hline SIM (core) & 80 & 150 & 140 & 130 & 120 \\
ASP (coat) & 60 & 120 & 120 & 120 & 120 \\
Extrusion direction & & & & \\
\cline { 2 - 5 }
\end{tabular}


Table 3: List of ASP formulations used for preliminary investigation of the processability of selected polymers. Formulations were processed using a co-rotating twin screw extruder operated at $50 \mathrm{rpm}$.

\begin{tabular}{|c|c|c|c|c|c|c|c|c|c|c|c|}
\hline Formulation & Aspirin & Soluplus ${ }^{\oplus}$ & $\begin{array}{c}\text { Eudragit }^{\oplus} \\
\text { EPO } \\
\text { g } \\
\end{array}$ & $\begin{array}{l}\text { PVP- } \\
\text { VA64 } \\
\text { g } \\
\end{array}$ & $\mathbf{g}$ & $\begin{array}{c}\text { Lutrol } \\
\text { F68 } \\
\text { g } \\
\end{array}$ & PEG200 & $\begin{array}{c}\text { HME } \\
\text { Temperature } \\
{ }^{\circ} \mathrm{C} \\
\end{array}$ & $\begin{array}{c}\text { Measured drug } \\
\text { loading* } \\
\text { wt\% }\end{array}$ & $\begin{array}{c}\text { Free SA } \\
\text { content as \% of } \\
\text { declared ASP** } \\
\text { wt\% }\end{array}$ & $\begin{array}{c}\% \text { ASP Release } \\
\text { on declared } \\
\text { ASP @ 45min } \\
\% \\
\end{array}$ \\
\hline ASP 1 & 2.000 & 8.000 & - & - & - & - & - & 120 & $20.57 \pm 1.38$ & $0.21 \pm 0.07$ & $17.31 \pm 4.31$ \\
\hline ASP 2 & 2.000 & 6.400 & - & - & - & 1.600 & - & 120 & $20.99 \pm 1.04$ & $0.29 \pm 0.05$ & $20.62 \pm 2.88$ \\
\hline ASP 3 & 2.000 & - & 7.200 & - & - & - & 0.800 & 140 & $15.49 \pm 0.65$ & $40.81 \pm 1.15$ & - \\
\hline ASP 4 & 2.000 & - & 3.600 & 3.600 & - & - & 0.800 & 140 & $15.37 \pm 0.96$ & $33.17 \pm 2.64$ & - \\
\hline ASP 5 & 2.000 & - & 3.600 & 3.600 & - & - & 0.800 & 120 & $18.18 \pm 0.39$ & $39.37 \pm 1.79$ & - \\
\hline ASP 6 & 2.000 & - & 3.600 & 3.600 & - & - & 0.800 & 100 & $19.82 \pm 0.34$ & $31.91 \pm 0.64$ & - \\
\hline ASP 7 & 2.000 & - & - & 8.000 & - & - & - & 120 & $21.00 \pm 0.83$ & $0.59 \pm 0.25$ & $94.67 \pm 3.97$ \\
\hline ASP 8 & 2.000 & - & - & 7.600 & - & - & 0.400 & 120 & $21.28 \pm 1.23$ & $1.43 \pm 0.22$ & $91.42 \pm 2.45$ \\
\hline ASP 9 & 2.000 & - & - & 7.200 & - & - & 0.800 & 100 & $21.62 \pm 0.81$ & $0.85 \pm 0.69$ & $94.08 \pm 1.56$ \\
\hline ASP 10 & 2.000 & - & - & 7.600 & 0.400 & - & - & 120 & $20.72 \pm 1.37$ & $1.62 \pm 0.54$ & $85.24 \pm 0.13$ \\
\hline ASP 11 & 2.000 & - & - & 7.200 & 0.800 & - & - & 100 & $19.32 \pm 3.62$ & $0.29 \pm 0.11$ & $77.81 \pm 3.17$ \\
\hline
\end{tabular}

$690 \quad *$ The "measured drug loading" takes into account both ASP and SA recovered from content uniformity test.

**Free SA assessment - The compendial acceptable level of SA content in a ASP formulation should be $<3 \%$ of the declared ASP content. 
Table 4: Commonly used polymers in delayed release drug delivery systems with $\mathrm{pH}$ threshold and GIT site of delivery ${ }^{26,27}$.

\begin{tabular}{|c|c|c|}
\hline Polymer & pH threshold for dissolution & Targeted site for GI delivery \\
\hline Eudragit $^{\oplus}$ L100-55 & 5.5 & Duodenum \\
\hline HPMC phthalate 55 & 5.5 & Duodenum \\
\hline HPMC-AS LF & 5.5 & Duodenum \\
\hline HPMC-AS MF & 6 & Jejunum \\
\hline Eudragit $^{\oplus}$ L100 & 6 & Jejunum \\
\hline HPMC-AS HF & 6.8 & Ileum \& Colon \\
\hline Eudragit $^{\circ}$ S100 & 7 & Colon \\
\hline
\end{tabular}


Table 5: List of SIM formulations investigated for the processability of selected polymers. Formulations were processed at $50 \mathrm{rpm}$.

\begin{tabular}{|c|c|c|c|c|c|c|}
\hline $\begin{array}{c}\text { Formulation } \\
\text { No. }\end{array}$ & $\begin{array}{c}\text { SIM } \\
\mathbf{g}\end{array}$ & $\begin{array}{l}\text { HPMC-AS (HF) } \\
\mathrm{g}\end{array}$ & $\begin{array}{l}\mathrm{L-100} \\
\mathrm{g}\end{array}$ & $\begin{array}{l}\text { L-100-55 } \\
\mathrm{g}\end{array}$ & $\begin{array}{c}\text { TEC } \\
\mathbf{g}\end{array}$ & $\begin{array}{c}\text { TPGS } \\
\text { g }\end{array}$ \\
\hline SIM 1 & 0.500 & 4.275 & 4.275 & - & 0.950 & - \\
\hline SIM 2 & 1.000 & 4.050 & 4.050 & - & 0.900 & - \\
\hline SIM 3 & 2.000 & 3.600 & 3.600 & - & 0.800 & - \\
\hline SIM 4 & 0.500 & 3.800 & 3.800 & - & 1.900 & - \\
\hline SIM 5 & 0.500 & 4.275 & 2.1375 & 2.1375 & 0.950 & - \\
\hline SIM 6 & 0.500 & 4.275 & 2.1375 & 2.1375 & 0.950 & 1.000 \\
\hline SIM 7 & 0.500 & 2.850 & 2.850 & 2.850 & 0.950 & - \\
\hline SIM 8 & 0.500 & 2.850 & 2.850 & 2.850 & 0.950 & 1.000 \\
\hline
\end{tabular}

700 


\section{Co-extrusion Die, Co-extrudate Fixed Dose Combination and Release Profile} $338 \times 190 \mathrm{~mm}(54 \times 54$ DPI) 